\title{
Vulnerability of China's nearshore ecosystems under intensive mariculture development
}

\author{
Hui Liu ${ }^{1} \cdot$ Jilan $\mathrm{Su}^{2}$ \\ Received: 31 March 2015 / Accepted: 13 August 2015 /Published online: 2 September 2015 \\ (C) The Author(s) 2015. This article is published with open access at Springerlink.com
}

\begin{abstract}
Rapid economic development and increasing population in China have exerted tremendous pressures on the coastal ecosystems. In addition to land-based pollutants and reclamation, fast expansion of largescale intensive mariculture activities has also brought about additional effects. So far, the ecological impact of rapid mariculture development and its large-scale operations has not drawn enough attention. In this paper, the rapid development of mariculture in China is reviewed, China's effort in the application of ecological mariculture is examined, and the vulnerability of marine ecosystem to mariculture impact is evaluated through a number of examples. Removal or reduced large and forage fish, due to both habitat loss to reclamation/ mariculture and overfishing for food or fishmeal, may have far-reaching effects on the coastal and shelf ecosystems in the long run. Large-scale intensive mariculture operations carry with them undesirable biological and biochemical characteristics, which may have consequences on natural ecosystems beyond normally perceived spatial and temporal boundaries. As our understanding of possible impacts of large-scale intensive mariculture is lagging far behind its development, much research is urgently needed.
\end{abstract}

Responsible editor: Philippe Garrigues

Jilan $\mathrm{Su}$

sj1@sio.org.cn

1 Yellow Sea Fisheries Research Institute, Chinese Academy of Fishery Sciences, Qingdao, China

2 Second Institute of Oceanography, State Oceanic Administration, Hangzhou, China
Keywords Large-scale intensive mariculture - Impact on marine ecosystems $\cdot$ Sustainable development $\cdot$ Ecosystem approach to aquaculture

\section{Introduction}

Since the early 1980s, China's economy has developed rapidly with an average annual GDP growth rate over $9 \%$, according to its National Bureau of Statistics. The growth rate of the 11 provinces and metropolises along the coasts exceeded $10 \%$. In fact, with only $13 \%$ of China's land area, in 2011, the 11 coastal provinces and metropolises housed about $42 \%$ of its population and produced over $57 \%$ of the national GDP (CCICED Task Force 2013).

Rapid economic growth and urbanization have brought about tremendous pressure on the coastal and marine ecosystems, resulting in the loss or deterioration of many of their services. Land-based pollutant and coastal reclamation are the two most detrimental factors to the health of the ecosystems (CCICED Task Force 2013). According to the official bulletin, in 2009, over half of China's nearshore waters were classified as below the water quality standard and about $20 \%$ as severely below standard. Occurrence of recorded events of harmful algal blooms (HABs) rose sharply to about 80 yearly, covering a total area exceeding $15,000 \mathrm{~km}^{2}$ (op cit). Between 1990 and 2008, the average reclamation area in China reached $285 \mathrm{~km}^{2}$ yearly and a further $5780 \mathrm{~km}^{2}$ was planned for over the next 10 years: The fast pace of reclamation has caused significant coastal landscape fragmentation and loss of biodiversity, as well as destruction of habitats for fish and loss of feeding grounds for shorebirds, leading to sharp decline in fisheries resources and bird species (Wang et al. 2014). In addition, overfishing, rapid expansion of mariculture, and construction of large number of hydraulic works on land all 
had compounded the impacts on China's coastal and marine ecosystems (CCICED Task Force 2013).

Spurred by both improved culture technology and rise in domestic demand for high-quality seafood, there has been a revolutionary growth of mariculture in China over the last 30 years. China is credited with 63.3 and $54 \%$, respectively, of the world's farmed marine food fish and aquatic plant production (FAO 2014), which are usually farmed in large-scale aquaculture operations. For such high production, extensive patches of tidal flats and nearshore waters have been converted for mariculture use. However, so far, the ecological impact of rapid mariculture development and its large-scale operations has not drawn sufficient attention in China. Attention is usually directed at the food provision function of mariculture, while the interference of mariculture with other ecosystem services has not been fully recognized.

In this paper, the rapid development of mariculture in China is reviewed, China's effort in the implementation of ecological mariculture practices is examined, and the vulnerability of marine ecosystems to impacts of mariculture is evaluated, pertaining to large-scale operations. Considering the current scale of mariculture worldwide and its significant upward trend, impacts of the world's intensive mariculture on the ocean ecosystems are far from negligible. Understanding the true state of impact of intensive mariculture on coastal and marine ecosystems will facilitate consideration of precautionary measures to ensure sustainable growth of world mariculture.

\section{Mariculture in China}

Along with the world's rapid growth in mariculture over the recent decades, China's mariculture has also undergone unprecedented development (Fig. 1). Since the middle 1970s, both the mariculture production and capture fisheries experienced fast growth. However, after the middle 1990s, the capture fisheries became stagnant while mariculture kept on expanding. The ratio between the mariculture production and fishery catch was almost nil in early 1950 s, reached $20 \%$ in $1975,50 \%$ in 1988 , and $100 \%$ in 2006, and stood at $140 \%$ in 2013. This is in sharp contrast to the ratio for Europe (18\%) and for other continents $(<15 \%)$ (data source: FAO FishStatJ). In 2012 China's mariculture contributed to 54 and $63.3 \%$, respectively, of the world's farmed aquatic plants (largely seaweeds) and marine food fish production (FAO 2014). In light of the depletion of wild fish stocks and the continuing rise in domestic seafood demand, mariculture will undoubtedly lead the future growth of Chinese aquaculture in the long run.

Throughout the 1950 1980, mariculture species in China were largely confined to seaweeds and bivalves, which are extractive species relying on natural supply of nutrients and plankton. Monoculture on longlines over tidal flats was the main type of operation. Commercial culturing of shrimp, finfish, and other high-value species began in the early 1980s, when land-based hatcheries, earthen ponds, and net cages were rapidly set up. The trend of "fishing down and farming up the food web" has been significant in the world fishery industry for decades (Naylor et al. 2000), and China is no exception. In the last 15 years, mariculture production of fed species (finfish and crustaceans) increased sharply from $<5$ to $>15 \%$, showing a clear upward trend into the future (Fig. 2). This reflects the increased domestic market demand for highvalue seafood, corresponding to the economic growth in China. At the same time, this will no doubt bring about increased wastes from mariculture, because, unlike the freshwater finfish which are mostly planktonic filter feeders or omnivorous, marine finfish and crustaceans are generally carnivorous and high in trophic level. Paying attention to this trend is important
Fig. 1 Growth of mariculture production and fishery catch during 1950-2013. The number above each red arrow denotes the ratio of "aquaculture/fishery catch" for that year (data source: MOA 1979-2014)

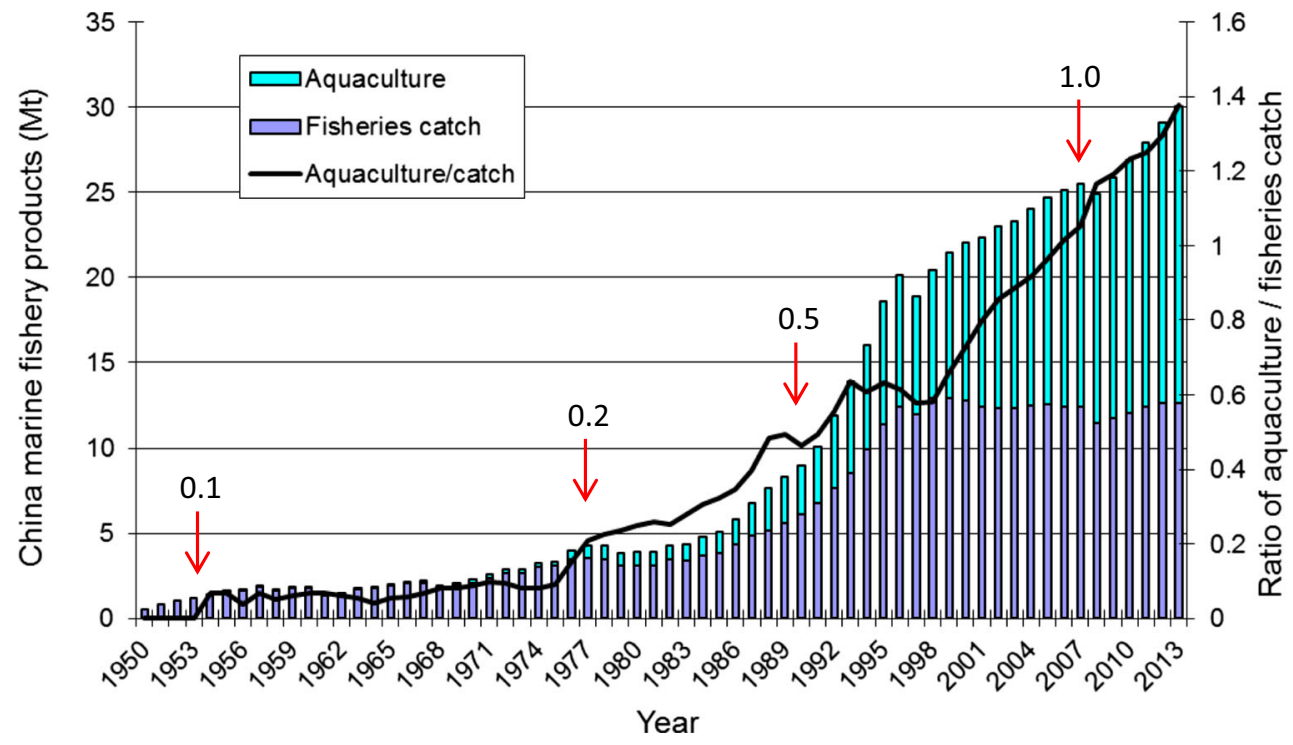


Fig. 2 Change of the composition of China's mariculture over time (data source: MOA 1998-2014)

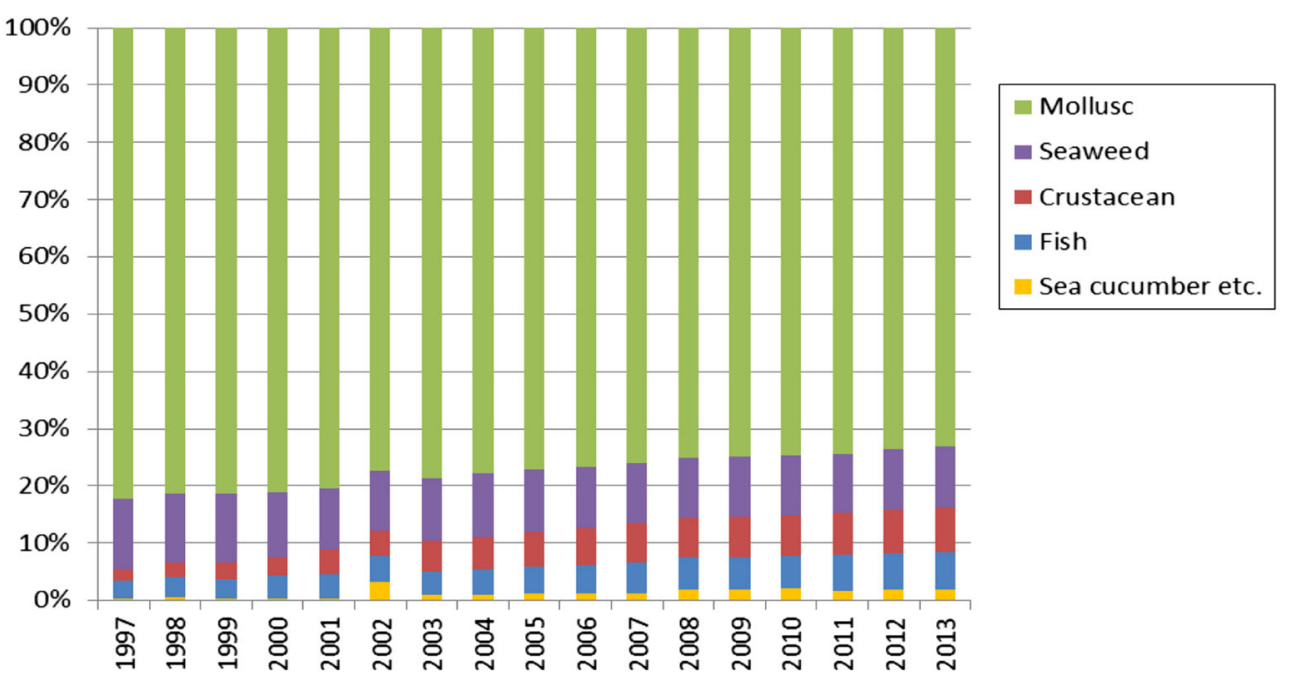

for rational planning and ecosystem-based management of mariculture.

Along with the increase of production, large portions of area from both the intertidal wetlands and nearshore waters of China were used for mariculture (Fig. 3). According to the Chinese fishery statistics (MOA 2014), the total mariculture acreage amounted to 2.32 Mha in 2013, among which 0.8 Mha was converted from intertidal wetlands (nearly one third of China's total) and 0.9 Mha from the nearshore waters (nearly $10 \%$ of China's total) was used for mariculture purpose.

\section{China's approach to ecological mariculture}

Aquaculture is basically an economic activity that consumes resources, impacts on biodiversity in different levels and ways, and discharges wastes, hence affecting the environment (e.g., Naylor et al. 2000). With the worldwide rapid development of aquaculture since the 1970s, especially in developing countries, there was first a focus on productivity and benefits, leading to a general scaling up and overstocking. The resulting

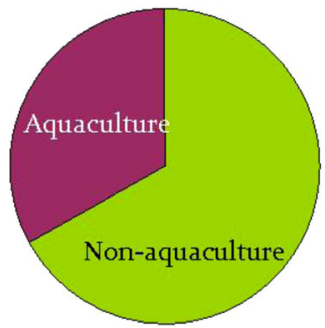

Intertidal wetlands
(2013)

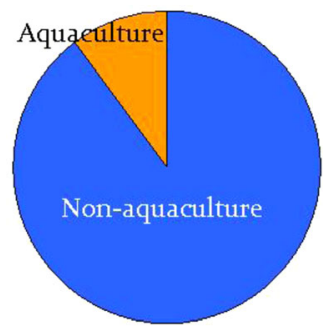

Nearshore waters
Fig. 3 Portion of area used for mariculture in, respectively, intertidal wetlands and nearshore waters of China in 2013. Calculation based on coastal wetland area data from the SFA (2011) and aquaculture area data from MOA (2014) aquaculture epidemics and mass mortalities raised awareness of ecological carrying capacity of the aquaculture systems (e.g., Grant et al. 2007). This concept soon evolved into ecological aquaculture, with ecosystem approach to aquaculture (EAA) as its implementation strategy (Soto et al. 2008).

Conceptually, EAA embodies the principle of ecosystembased management by promoting conservation and sustainable use of resources. In implementing EAA, it is necessary to define the ecosystem boundaries in both space and time. For this, three levels of scale have been identified, namely, the farm, the watershed/aquaculture zone, and the global (Soto et al. 2008). In practice, boundaries for the second level, i.e., the watershed/aquaculture zone level, sometimes are not easy to delineate, both managerially and ecologically. For a fjordlike inlet where the physical boundaries are more or less defined, management tools including analysis models for evaluating aquaculture in an ecosystems approach were developed and proved to be useful (Nunes et al. 2011). However, because of the lack of a good understanding of the interaction between a mariculture operation and the marine ecosystems at large, presently, there are no agreed-on guidelines or practical measures for implementing EAA at the level of the watershed/ aquaculture zone.

One innovative approach within EAA is the so-called integrated multi-trophic aquaculture (IMTA), in which multitrophic species with complimentary trophic functions are cultured together. Traditional IMTA has been practiced in the world for thousands of years, including ancient China (Costa-Pierce 2010). Modern polyculture methods in China, as one of the eight techniques embodying China's freshwater aquaculture, were reviewed for the first time in 1959 (CoCFAE 1961).

With the development of intensive aquaculture worldwide since the 1970s, monoculture of omnivorous or carnivorous marine species at high densities, including finfish and crustacean species, was initially carried out in China. The 
production boom in late 1980s and early 1990s brought about environmental pollution and disease outbreak among the stocks, leading to a crash in harvest. At the same time, technology improvement allowed for restructuring of the existing culture systems. There was then a clear transition in China from intensive monoculture to polyculture. The first successful attempt in marine polyculture was conducted in 1975, when kelp Laminaria japonica and mussels Mytilus edulis were co-cultured (Xie 1981; Dong 2011). Soon, polyculture in China evolved such that fed (fish and shrimp) and non-fed species (bivalves and seaweeds) were cultured together, where the non-fed species served as a means to recycle wastes and reduce pollution (e.g., Wu et al. 1980; Zhu 1981). Thus, the ecosystem perspective in traditional mulberry-fish pond system from ancient China regained appreciation. Such IMTA mode ecological aquaculture is now commercially practiced in China (Fang 1996; Dong 2011).

A major IMTA demonstration site in China is Sanggou Bay, at the tip of Shandong Peninsula in eastern China, where, according to local statistics, seaweed, shellfish, and finfish are cultured at a ratio of approximately 7:3:1 with an annual seaweed production of about 200 thousand tons (Zhang XJ, Head of Ocean and Fishery Bureau of Rongcheng, private communication). Based on both research findings and technology improvement, the ratio and layout of the seaweed longlines, shellfish lantern nets, and finfish net cages were constantly optimized to minimize the environmental impact from this major IMTA system (Tang et al. 2013, Shi et al. 2013). Although IMTA has become an important component for mariculture in China, there is no official statistics on its scale and total production because it is not yet classified as one standard aquaculture mode.

At the same time, IMTA has been met with worldwide enthusiasm during the last decade, as an effective way to deal with the wastes and improve the output of aquaculture (Barrington et al. 2009; Chopin 2012). In the present practice of IMTA, there are various approaches to achieve the basic goals that feed and wastes are recycled within the system. With different species composition and spatial configuration, IMTA has been applied to both pond and open-water mariculture systems. Although there were attempts to study the nutrient balance within an IMTA system from a modeling point of view (e.g., the study of ratios between fed and extractive species in IMTA farms (Reid et al. 2013)), lack of thorough understanding of environmental impact of IMTA remains one major concern (e.g., IMTA White Paper 2010).

From the point of view of EAA, boundary delineation of an IMTA system at the watershed/aquaculture zone level is often not straightforward. This results in rather complicated interaction between the culture system and the natural habitats. For example, large-scale IMTA in shallow bay will significantly alter the tidal currents, resulting in a reduced flushing capability of the bay, as well as insufficient nutrient supply to the bay from the offshore water (Shi et al. 2011). In addition, organic wastes do accumulate in the sediments of IMTA area and alter both the benthic and water column chemical parameters (Ren et al. 2014). Given the physical conditions of any particular IMTA site, it is extremely difficult, if not impossible, to recycle all the nutrients and wastes within an IMTA system.

\section{Vulnerability of the nearshore ecosystem}

As commented in the "Introduction" section, over the last 30 years, the nearshore ecosystems of China have been under multiple pressures of human activities, including land-based pollutants, reclamation, port construction, overfishing, and mariculture. Early concern about the impact from mariculture was limited to its waste discharge pollution and escapees. However, as China's mariculture rapidly expands, there are evidences now that large-scale intensive mariculture may bring about undesirable ecological consequence far beyond the normally perceived boundaries of its operation. The combined impact from mariculture and other human activities has an amplification effect that significantly increases the vulnerability of China's coastal and marine ecosystems. In the following, we will use a few examples to illustrate this point.

\section{Degradation and destruction of natural habitats}

As is well known, intertidal wetlands and nearshore waters are critical habitats for many marine organisms, including both large and forage fish. As extensive tidal flats and wetlands are transformed to aquaculture ponds, the natural ebb and flow of tides disappear, along with the local benthic organisms and migrating shore birds (Yang et al. 2004, Chen and Ouyang 2014). Mariculture not only introduces pollutants into nearshore material cycle, but also interferes with local hydrologic processes which can disrupt the success of recruitment in the early life of fisheries (e.g., Dong et al. 2007). In open-water aquaculture, the environmental impact is heavily influenced by local circulation (Han and Liu 2014). It is noteworthy that mariculture impact on a sheltered bay is usually more significant due to its limited environmental carrying capacity. Large-scale net cages and longline facilities in shallow bays significantly slow down the tidal currents, resulting in weakened flushing capability of the bay, reduced nutrient supply to the inner bay, increased deposition, and reduced productivity of phytoplankton (Ji et al. 1998; Liu et al. 2004; Shi et al. 2011). In addition, accumulation of waste deposits under shellfish longlines or finfish net cages may severely affect the macro-benthos and change their biodiversity, composition, and distribution (Gao et al. 2003; Yang et al. 2007; Wang et al. 2011). In the long run, the establishment of a mariculture system may result in fragmentation of the original natural 
ecosystems and disappearance or significant change in some of the original biotic communities (Liu and Fang 2014).

Furthermore, mariculture also imposes deleterious effects on the natural fauna and flora through its chemical or pharmaceutical discharge. To eliminate harmful or undesirable organisms in many of the extensive pond mariculture, pellouxite and other disinfectants have been used in high concentrations before or during the culture period (Luo 2012). When the treated water is discharged without further treatment, these chemicals will invariably cause high mortality to the nearby wild fauna and flora.

Although such impacts are well known, in the case of China, the magnitude of these impacts on the nearshore ecosystems needs to be assessed against the scope of the human activities. As discussed in the "Introduction" section, natural wetlands in China suffered great loss and degradation over decades. More than $50 \%$ of the coastal wetlands were lost due to reclamation for various uses, including mariculture (An et al. 2007). The loss of associated ecosystem services due to reduced purification capacity, failure in recruitment of fishery stock, and reduced biodiversity was estimated to amount to 46 billion USD per year (op cit).

For example, the Laizhou Bay of Bohai Sea has always been used as spawning grounds for many fishery species of the Bohai Sea and Yellow Sea (Deng and Jin 2000; Xu and Chen 2010). However, presently, most of the estuaries and wetlands around the bay are severely affected by mariculture activities (Fig. 4). Furthermore, not shown in the figure, there are also large areas of longline mariculture over the shallow waters in the bay. It is possible that most of the nursery grounds for the fisheries are either lost or severely degraded. Thus, in addition to overfishing, reclamation and mariculture activities may also contribute to the collapse of regional fishery (Zuo and Lin 2008; Wang et al. 2014).

The loss of coastal wetlands along with its biodiversity is not unique in China. As a matter of fact, there has been extensive loss of tidal flats around the whole Yellow Sea region, associated with economic development in China and the two Koreas. It was found that $28 \%$ of the Yellow Sea tidal flats existing in the 1980s had been reclaimed by the late 2000s (Murray et al. 2014).

\section{Pressure on wild fisheries}

There have been very few observations on the direct aquaculture impact on wild fishery, especially regarding a particular species and over a significant length of time. According to a 7year study in Canada (Loucks et al. 2014), net cage finfish aquaculture produced odors and changed benthic habitat and water quality, which may affect the behavior and movement of wild fishery species (e.g., lobster). It was found that, within 2 years of a finfish aquaculture operation, ovigerous lobsters abandoned the area and overall lobster abundance decreased;

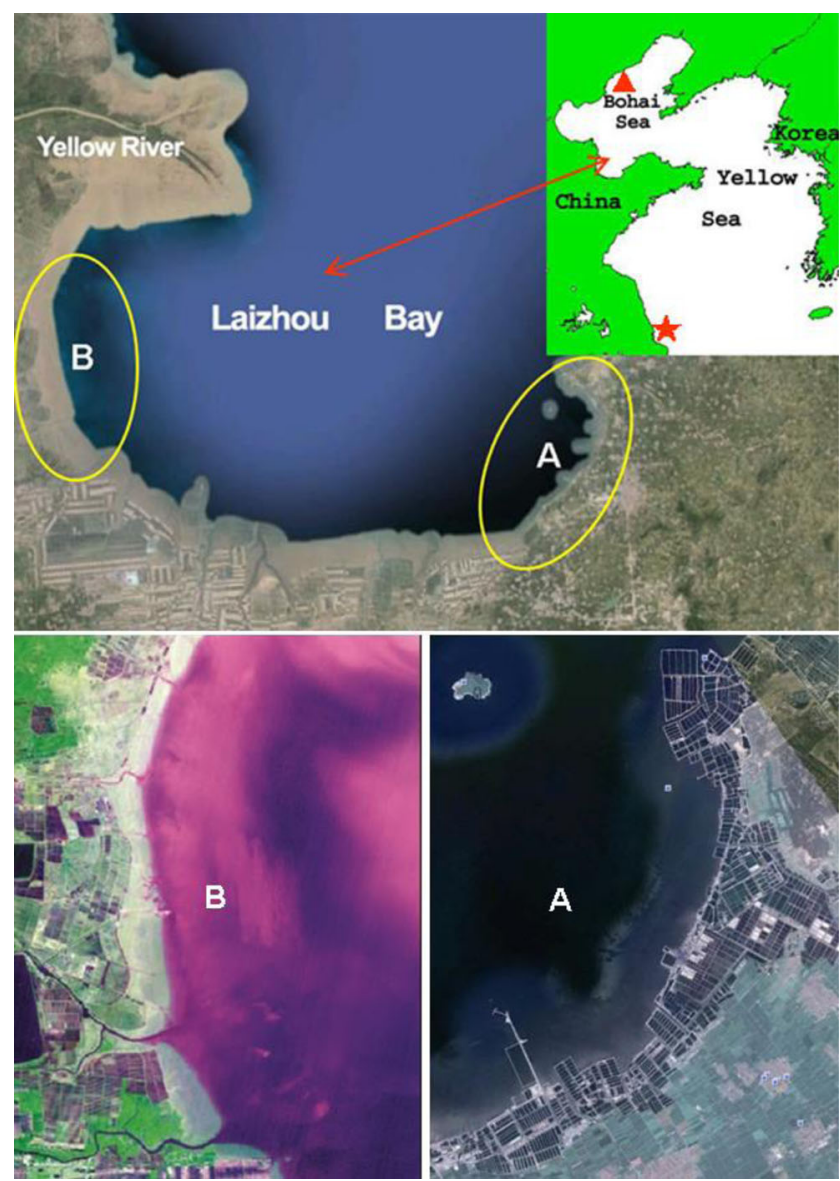

Fig. 4 Extensive mariculture facilities along the shores of the Laizhou Bay. In the inserted map on the top figure, the red triangle and star denote, respectively, the location of the large-scale bivalve culture and the extensive Su-Bei tidal shoals

the female lobsters returned to this area only when fish farming was discontinued. On the other hand, aquaculture may provide food for wild species. For example, aggregations of wild fish communities were repeatedly observed in the vicinity of aquaculture farms in the Mediterranean (Grigorakis and Rigos 2011).

In addition to habitats, marine capture fisheries and mariculture also compete for other ecosystem services, such as nutrients and feed, broodstock, and larval supply (Naylor et al. 2000). In China, the catch of wild broodstock for hatchery (such as Chinese shrimp Fenneropenaeus orientalis) and of young fish for grow-out or fattening (such as sea bass Lateolabrax maculatus and freshwater eel Anguilla japonica) has been going on for many years (Niu 1982; Gao and Zhang 2002; Zhi et al. 2013). The above-mentioned human activities together imposed devastating effect on the wild stock and also defeated large-scale restocking efforts conducted in China, including artificial reefs and annual release of tens of billions of fishery seedlings (Shan et al. 2012).

Another impact of mariculture on wild fishery is the harvest of forage fish, which is either directly fed to aquaculture 
or processed into fishmeal. Generally speaking, in China, about one third of forage fish (about $4 \mathrm{Mt}$ ) are fed directly to aquaculture species (Mai 2010), although there is large sitespecific variability. Annual production of these small forage fish amounted to several million tons, though not all such productions are recorded in the official fishery statistics (op cit). Statistics of specific forage fisheries varied widely over the decades, reflecting overfishing pressure on these species (Fig. 5).

Jackson et al. (2001) have shown that overfishing of large fish fundamentally altered coastal marine ecosystems during each of the cultural periods examined. Forage fish is also an important part of the regional marine ecosystems. With pressure from both habitat loss/degradation and overfishing, it is hard to imagine how the regional coastal and nearshore ecosystems will evolve when both the large and forage fisheries are destroyed.

\section{Proliferation of opportunistic species}

Since 2007, there has been yearly outbreak of large-scale green tides over the Yellow Sea in summer. In 2013, at its peak, it covered a total area $790 \mathrm{~km}^{2}$ distributed over a wide area of $29,700 \mathrm{~km}^{2}$, while, in 2014 , the numbers were, respectively, 540 and $50,000 \mathrm{~km}^{2}$ (SOA 2014, 2015). Figure 6 shows the distribution pattern of the green tides on 30 June 2013 and 14 July 2014. The green tides are caused by Ulva prolifera (Enteromorpha prolifera), a macro-algae species often found along the coasts of temperate Asia, including China. Proliferation of $U$. prolifera is associated with the large-scale mariculture system of Porphyra yezoensis over the extensive Su-Bei tidal shoals of China (Figs. 4 and 6) off the west boundary of the Yellow Sea (Liu et al. 2009).

Micropropagules of $U$. prolifera generally exist in the nearshore water of Yellow Sea. The micropropagule will grow only after attaching itself to a periodically exposed surface, including the rafts used for the P. yezoensis culture. A variety of macro-algae species would attach and grow on these rafts from late autumn, including U. prolifera, Ulva linza, Ulva compressa, Ulva intestinalis, and Ulva clathrata. U. prolifera became one of the most dominant species only in late March to mid-May (Fan et al. 2015). At the harvest of $P$. yezoensis in April, the attached macro-algae were stripped off and left on the shoals. Most of the macro-algae left on the shoals were drowned except $U$. prolifera which can float during photosynthesis. Once leaving the shoals, the floating $U$. prolifera would drift in an N-NE direction driven by the prevailing winds. The floating $U$. prolifera grew at an initial daily rate of 20-30\% and soon evolved to green tides (op cit). Some of the drifting green tides landed on the shores of Shangdong Province in June/July while the rest eventually sank offshore.

Figure 7 gives the yearly production, culture area, and productivity of the P. yezoensis culture in Jiangsu Province between 1988 and 2013 (most of this culture is over the Su-Bei Shoals). It is noted that the yearly production of $P$. yezoensis reached a plateau after 2007 even though the cultured area kept increasing. The productivity underwent a sharp drop then. The year 2007 was when the green tides over the Yellow Sea first became noticeable. From 2008 to the present, there is a yearly outbreak of green tides covering $250-2100 \mathrm{~km}^{2}$ distributed over $20,000-60,000 \mathrm{~km}^{2}$. It is possible that certain bloom-state threshold for the opportunistic species $U$. prolifera was reached after 2007, likely related to the size of the culture area of P. yezoensis (Fig. 7).

There is no reported estimate on the portion of the floating mass of $U$. prolifera that sink offshore, nor is there any study on the fate of these submerged macro-algae. It is well known that, in summer, the Yellow Sea Cold Water (YSCW), a water mass, occupies the central part of Yellow Sea deeper than $40 \mathrm{~m}$ below a sharp thermocline (e.g., Su 1998). Figures 7-8 and 7-6 in Hong (2012), respectively, showed that the bottom dissolved oxygen in YSCW is highest in spring and lowest in autumn, and in addition, over the past 30 years, it has a continuous decreasing trend with an average drop of about
Fig. 5 Fishery catch of anchovy and sandlance in China during 1989-2013 (data source: MOA (1990-2014))

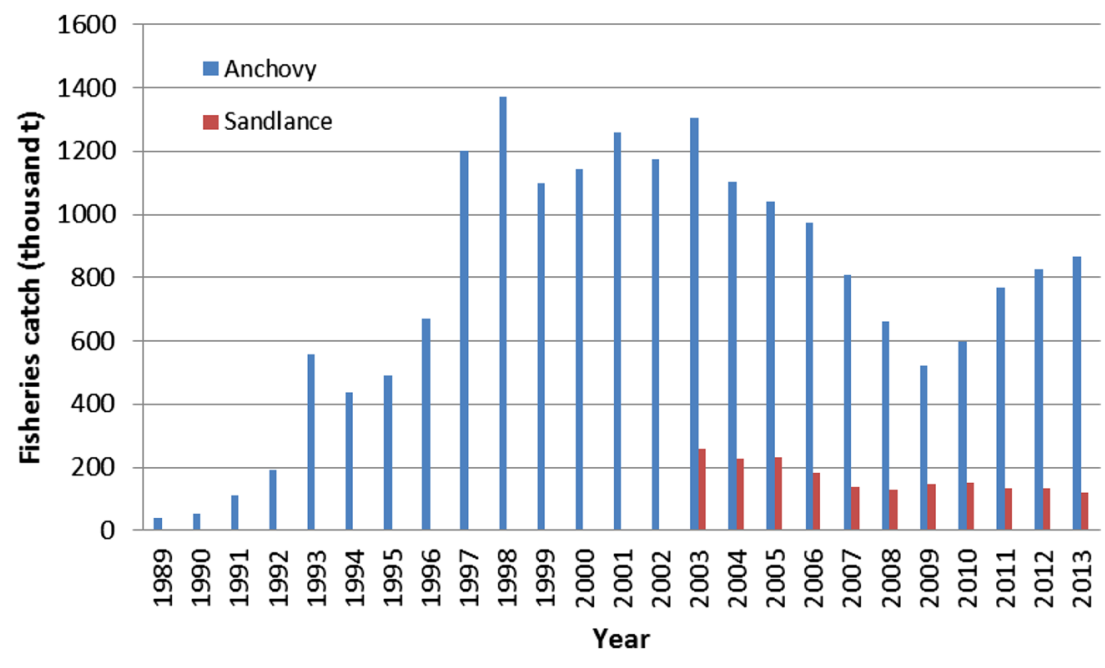


Fig. 6 Distribution pattern of the green tides over Yellow Sea on 30 June 2013 and 14 July 2014 (figure source: SOA 2014, 2015)

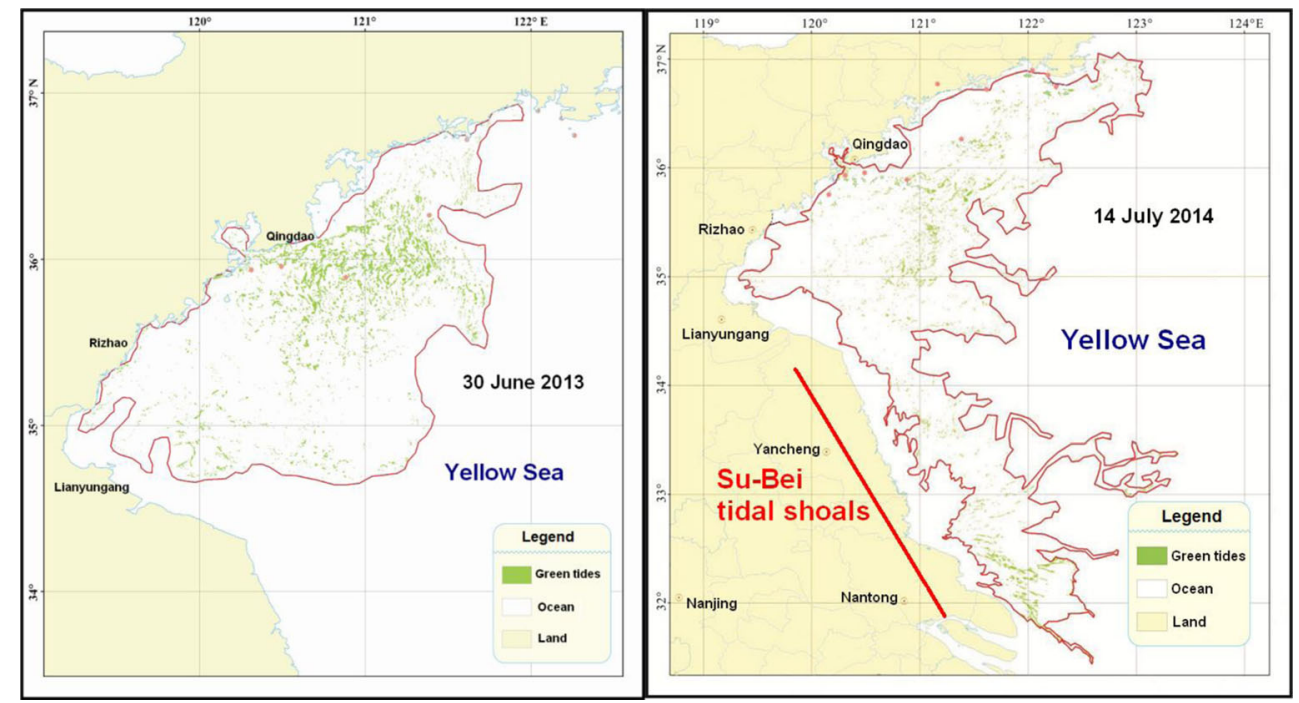

$0.77 \mathrm{mg} \mathrm{l}^{-1}$. A recent ocean acidification survey found that in late autumn of 2012, large area of YSCW had a saturation state of aragonite below 1.0 (SOA 2013), indicating a corrosive environment for many marine organisms (Fabry et al. 2008). It is known that YSCW serves as important oversummer grounds for Calanus sinicus, an important copepod providing a wide size spectrum of food for fish stocks (Wang et al. 2003). How the annual outbreak of $U$. prolifera blooms will exert further pressure on the ecosystem services of YSCW is yet to be studied.

\section{Alteration of biochemistry in water/sediment}

Although mariculture ponds and enclosures and nearshore longline culture areas are usually counted as artificial wetlands, they are fundamentally different from natural coastal wetlands because their ecosystem services are significantly different. Mariculture is also a major driver on changes in the biogeochemistry of its neighboring water and sediment.
The deleterious environmental effects of the intensive and industrialized mariculture have been well recognized (e.g., National Research Council 2010). Finfish cage culture can cause significant rise in dissolved nitrogen in water column, particulate phosphorous in sediment, and chemical oxygen demand (COD) in both the water column and sediment (e.g., Holby and Hall 1991; Wang 1998). Large-scale oyster (Crassostrea gigas) culture may alter the sediment geochemistry by raising $\mathrm{NH}_{4}{ }^{+}$and $\mathrm{HPO}_{4}{ }^{2-}$ by 7.7-11.5 and 1.8-8.0 times and sulfate reduction rates by 2.4-5.2 times (Hyun et al. 2013). Given the scale of bivalve culture in China (total annual production of $12.7 \mathrm{Mt}$ over a total area of 1.6 Mha) (MOA 2014), the biochemical alteration of inshore sediments is considered significant enough to induce eutrophication, change in $\mathrm{P} / \mathrm{N}$ ratio, and outbreaks of HABs (Bouwman et al. 2013). This was echoed by Hyun et al. (2013), who observed enhanced benthic microalgal biomass and primary production in the water column at the bivalve farms. As discussed in "China's approach to ecological mariculture" section, it is difficult even for an IMTA system to recycle all
Fig. 7 Yearly P. yezoensis culture production, culture area, and productivity in Jiangsu Province in 1988-2013 (source of data: MOA 1989-2014)

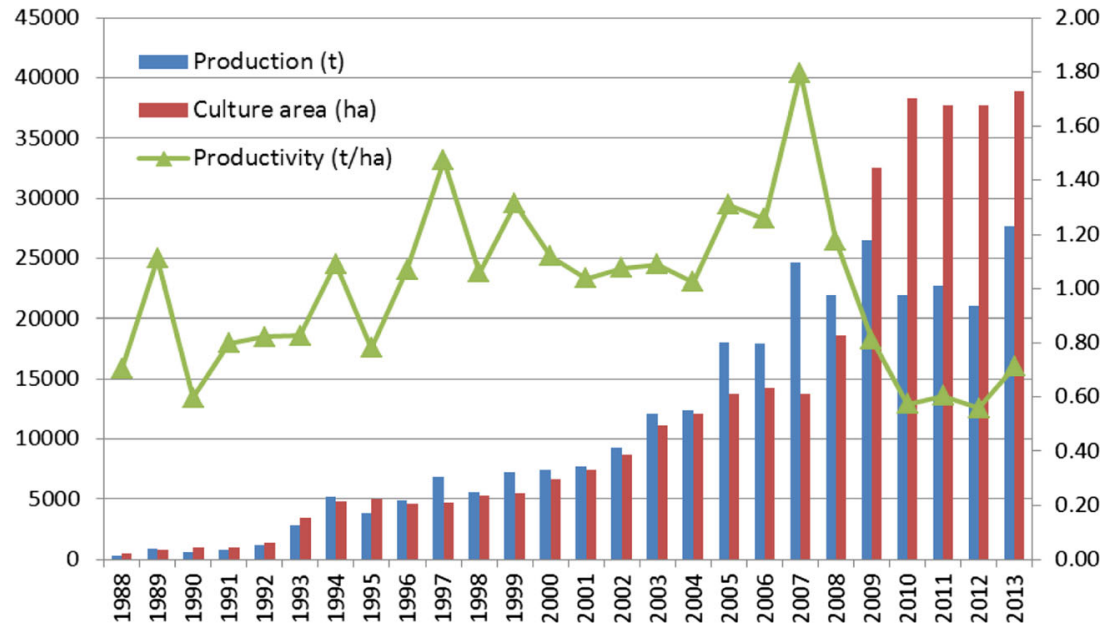


the nutrients and wastes within its system. Indeed, eutrophication effect of polyculture (with finfish, shellfish, and seaweed) can be significant in a sheltered bay (Zhang et al. 2003).

Nutrients in the reduced form in the ocean are of particular concern. For example, reduced $\mathrm{N}$ forms were preferentially taken up during the harmful microalgae blooms of Karenia mikimotoi and Prorocentrum donghaiense in nearshore waters of the East China Sea (Li et al. 2009). Both of these are common HAB species in coastal China, and the blooms of K. mikimotoi usually cause great losses in mariculture (SOA 2005-2015).

Among all forms of mariculture pollutions, direct release of nutrients in the reduced form into the ocean is of more concern (Bouwman et al. 2013). Laboratory experiments showed that ammonia and urea excreted by the cultured animals were readily taken up by phytoplankton and could stimulate their growth (Arzul et al. 1996; Yang et al. 2004). When the level of such nutrient is higher than the assimilative capacity of the marine area, it may fuel the production of algae on which mixotrophic HABs may feed (op cit). In turn, such mixotrophic HABs can kill or intoxicate the mariculture organisms and increase risks to human health. The scallop Argopecten irradians culture at the nearshore region of the northwestern Bohai Sea (Fig. 4) is number one in China by area scale (Zheng et al. 2011). Coincidentally, large-scale Aureococcus anophagefferens brown tides, a form of mixotrophic HABs, have occurred in the northwestern Bohai Sea in early summer for consecutive years since 2009 and have caused significant negative impacts on the scallop culture there (Zhang et al. 2012). China is the third country in the world hit by brown tides, but at a much greater scale. At its peak, the brown tides covered an area of over $3000 \mathrm{~km}^{2}$ (op cit).

Particulate wastes from aquaculture usually accumulate in nearby sediments, driving an increase in COD value. As organic matter is decomposed by microbes through respiration, the redox potential will decrease, leading to bottom dissolved oxygen (DO) depletion (Wang 1998). Accumulation of wastes and microbial/phytoplankton biomass in proximity to mariculture sites may give rise to hypoxia conditions resulting in an anoxic layer of sediment and bottom waters (Yang et al. 2004), and this develops very often in stratified water. In fact, seasonal bottom oxygen depletion in western Bohai Sea, especially in the vicinity of large-scale bivalve culture sites, has now become normality and is getting worse (Zhai et al. 2012). The progressive depletion in the summer bottom dissolved oxygen in Bohai is rather alarming and raises further concern about Bohai Sea's ecosystems. Observation showed that its minimum bottom oxygen level in August steadily dropped over the years, being $6.3 \mathrm{mg} \mathrm{l}^{-1}$ in 1982, $5.1 \mathrm{mg} \mathrm{l}^{-1}$ in 1992 , $4.5 \mathrm{mg} \mathrm{l}^{-1}$ in 2006, $3.5 \mathrm{mg} \mathrm{l}^{-1}$ in 2011, and below $3 \mathrm{mg} \mathrm{l}^{-1}$ in 2014 (Zhai Weidong, private communication). Analysis by Zhai et al. (2012) indicated that both the bottom DO depletion and acidification in summer were caused by remineralization of biogenic particles, which were supplied by either coastal HABs or regional nearshore mariculture.

\section{Conclusion}

As the world's population keeps on increasing with high aspiration for better life, rapid intensive reclamation and largescale mariculture practices will no doubt be replicated in developing countries around the world's coasts. Such human activities are conducted over intertidal wetlands and nearshore waters, which lie in a narrow strip along the coast. These habitats are critical in the life history of many species of large and forage fish. At the same time, overfishing, either for food or for fishmeal, exerts tremendous pressure on the stock of both large and forage fish. During past cultural periods, overfishing of large fish was shown to have fundamentally altered coastal marine ecosystems (Jackson et al. 2001). If the large and forage fish are sharply reduced, both the coastal and shelf ecosystems will likely be significantly altered.

Mariculture replaces intertidal wetlands with artificial wetlands and brings artificial ecosystems into nearshore waters. These artificial ecosystems bring with them different but undesirable biological and biochemical characteristics. Spatial and temporal extents of the effects of these artificial ecosystems, i.e., the boundaries for the watershed/aquaculture zone level, are often hard to define. The speed of mariculture development far outpaces the progress of our knowledge about its impacts. Examples given above show that the coastal and nearshore ecosystems are rather vulnerable when facing intensive large-scale mariculture development.

The fast pace of the worldwide coastal development will likely cause the coastal and nearshore ecosystems to evolve into states unfriendly to either the coastal communities or the ocean ecosystems at large. As our understanding of such possible changes is lagging far behind the economic and social development, much research is urgently needed, including those related to large-scale intensive mariculture.

Acknowledgments This work arises from two task force studies, the Problems Facing China's Sea Enclosing and Land Reclamation (20082009) and the Scientific Questions and Policy Recommendations for Ecosystem Eveluation and Management of Coastal Waters of China (2014-2016), both funded by the Chinese Academy of Sciences.

Open Access This article is distributed under the terms of the Creative Commons Attribution 4.0 International License (http:// creativecommons.org/licenses/by/4.0/), which permits unrestricted use, distribution, and reproduction in any medium, provided you give appropriate credit to the original author(s) and the source, provide a link to the Creative Commons license, and indicate if changes were made. 


\section{References}

An S, Li H, Guan B, Zhou C, Wang Z, Deng Z, Zhi Y, Liu Y, Xu C, Fang S, Jiang J, Li H (2007) China's natural wetlands: past problems, current status, and future challenges. Ambio 4:335-342

Arzul G, Clément A, Pinier A (1996) Effects on phytoplankton growth of dissolved substances produced by fish farming. Aquat Living Resour 9:95-102

Barrington K, Chopin T, Robinson S (2009) Integrated multi-trophic aquaculture (IMTA) in marine temperate waters. In: Soto D (ed) Integrated mariculture: a global review, vol 529, FAO Fish Aquac Tech Paper., pp 7-46

Bouwman L, Beusen A, Glibert PM, Overbeek C, Pawlowski M, Herrera J, Mulsow S, Yu RC, Zhou MJ (2013) Mariculture: significant and expanding cause of coastal nutrient enrichment. Environ Res Lett 8. doi:10.1088/1748-9326/8/4/044026

Chen JH, Ouyang L (2014) Let the migrating birds fly freely. Ecol Econ 30(11):10-13 (in Chinese)

Chopin T (2012) Integrated multi-trophic aquaculture (IMTA). In: Meyers R (ed) Encyclopedia of sustainability science and technology. Springer Reference, N.Y., pp 184-205

Committee on China's Freshwater Aquaculture Experience (CoCFAE) (1961) China freshwater aquaculture. Science Press, Beijing (in Chinese)

Costa-Pierce BA (2010) Sustainable ecological aquaculture systems: the need for a new social contract for aquaculture development. Mar Technol Soc J 44:88-112

Deng JY, Jin XS (2000) Study on fishery biodiversity and its conservation in Laizhou Bay and Yellow River Estuary. Zool Res 21:76-82 (in Chinese)

Dong SL (2011) History, principles, and classification of integrated aquaculture in China. J Fishery Sci China 18:1202-1209 (in Chinese)

Dong LX, Su JL, Deng JY, Chen Q (2007) The importance of estuarine gravitational circulation in the early life of the Bohai Penaeid Prawn. J Mar Syst 67:253-262

Fabry VJ, Seibel BA, Feely RA, Orr JC (2008) Impacts of ocean acidification on marine fauna and ecosystem processes. ICES J Mar Sci 65:414-432

Fan SL, Fu MZ, Wang ZL, Zhang XL, Song W, Li Y, Liu GX, Shi XY, Wang XN, Zhu MY (2015) Temporal variation of green macroalgal assemblage on Porphyra aquaculture rafts in the Subei Shoal, China. Estuar, Coastal Shelf Sci. doi:10.1016/j.ecss.2015.03.016

Fang JG, Sun HL, Yan JP, Kuang SH, Li F, Gary F, Grant J (1996) Polyculture of scallop Chlamys farreri and kelp Laminria japonica in Sungo Bay. Chin J Oceanol Limnol 14(4):322-329 (in Chinese)

FAO (2014) The state of world fisheries and aquaculture 2014. Rome. $223 \mathrm{pp}$

Gao HD, Zhang SR (2002) Discussions on sea bass seedling resource management measures. Hebei Fish 122:52 (in Chinese)

Gao AG, Yang JY, Chen QZ, Wang ZP, Zhang J, Dong YT, Ning XR (2003) Comparative studies on macrobenthos between cultured and non-cultured areas in Xiangshan Bay. J Fish China 27(1):25-31 (in Chinese)

Grant J, Curran KJ, Guyondet TL, Tita G, Bacher C, Koutitonsky V, Dowd M (2007) A box model of carrying capacity for suspended mussel aquaculture in Lagune de la Grande-Entree, Iles-de-laMadeleine, Quebec. Ecol Model 200:193-206

Grigorakis K, Rigos G (2011) Aquaculture effects on environmental and public welfare - the case of Mediterranean mariculture. Chemosphere 855:899-919

Han QX, Liu DY (2014) Review on the effect of coastal bivalve raft mariculture on macrobenthic assemblages. Mar Sci Bull 33(3): 352-359 (in Chinese)

Holby O, Hall PO (1991) Chemical fluxes and mass balances in a marine fish cage farm II. Phosphorus. Mar Ecol Prog Ser 70:263-272
Hong HS (ed) (2012) Regional oceanography of china seas-chemical oceanography. Ocean Press, Beijing, 374pp (in Chinese)

Hyun JH, Kim SH, Mok JS, Lee JS, An SU, Lee WC, Jung RH (2013) Impacts of long-line aquaculture of Pacific oysters (Crassostrea gigas) on sulfate reduction and diffusive nutrient flux in the coastal sediments of Jinhae-Tongyeong, Korea. Mar Pollut Bull 74:187198

IMTA White Paper (2010) White paper integrated multi-trophic aquaculture: a workshop. September 14-15, 2010. Port Angeles, Washington http://www.nmfs.noaa.gov/aquaculture/docs/imta/ imta_white_paper.pdf Accessed on February 27, 2015.

Jackson JBC, Kirby MX, Wolfgang HB, Bjorndal KA, Botsford LW, Bourque BJ, Bradbury RH, Cooke R, Erlandson J, Estes JA, Hughes TP, Kidwell S, Lange CB, Lenihan HS, Pandolfi JM, Peterson CH, Steneck RS, Tegner MJ, Warner RR (2001) Historical overfishing and the recent collapse of coastal ecosystems. Science 293:629-638

Ji RB, Mao XH, Zhu MY (1998) Impacts of coastal shellfish aquaculture on bay ecosystem. J Oceanogr Huanghai Bohai Seas 16(1):21-27 (in Chinese)

Li J, Glibert PM, Zhou MJ, Lu SH, Lu DD (2009) Relationships between nitrogen and phosphorus forms and ratios and the development of dinoflagellate blooms in the East China Sea. Mar Ecol Prog Ser 383: $11-26$

Liu H, Fang J, Zhu J, Dong S, Wang F, Liang X, Zhang J, Lian Y, Wang L, Jiang W (2004) Study on limiting nutrients and phytoplankton at long-line-culture areas in Laizhou Bay and Sanggou Bay, northeastern China. Aquat Conserv Mar Freshwat Ecosyst 14(6):551-574

Liu DY, Keesing JK, Xing QG, Shi P (2009) World's largest macroalgal bloom caused by expansion of seaweed aquaculture in China. Mar Pollut Bull 58:888-895

Liu H, Fang JG et al (2014) Environmental impact of large scale mariculture. In: Su JL (ed) Scientific issues and policy recommendations on ecosystem safety of ocean and coastal engineering in China. Science Press, Beijing, In Chinese

Loucks RH, Smith RE, Fisher EB (2014) Interactions between finfish aquaculture and lobster catches in a sheltered bay. Mar Pollut Bull $88: 255-259$

Luo R (2012) Pay attention to disappearing coastal wetlands. China Nat 9:8-11 (in Chinese)

Mai KS (2010) Achievements and prospects for China aquaculture and feed industry. Sci Fish Aquac 11:1-2 (in Chinese)

Ministry of Agriculture (MOA) (1979-2014) China fishery statistical yearbook. China Agriculture Press, Beijing (in Chinese)

Murray NJ, Clemens RS, Phinn SR, Possingham HP, Fuller RA (2014) Tracking the rapid loss of tidal wetlands in the Yellow Sea. Front Ecol Environ 12:267-272. doi:10.1890/130260

National Research Council (2010) Ecosystem concepts for sustainable bivalve mariculture. National Academies Press, Washington DC. http:// www.nap.edu/catalog/12802.html Accessed on March 5, 2015

Naylor RL, Goldburg RJ, Primavera JH, Kautsky N, Beveridge MCM, Clay J, Folke C, Lubchenco J, Mooney H, Troel M (2000) Effect of aquaculture on world fish supplies. Nature 405:1017-1024

Niu ZZ (1982) Several technical issues on gathering and transporting shrimp broodstock. Hebei Fisheries Sci Technol 5:17-19 (in Chinese)

Nunes JP, Ferreira JG, Bricker SB, O’Loan B, Dabrowski T, Dallaghan B, Hawkins AJS, O'Connor B, O'Carroll T (2011) Towards an ecosystem approach to aquaculture: assessment of sustainable shellfish cultivation at different scales of space, time and complexity. Aquaculture 315:369-383

Reid GK, Chopin T, Robinson SMC, Azevedo P, Quinton M, Belyea E (2013) Weight ratios of the kelps, Alaria esculenta and Saccharina latissima, required to sequester dissolved inorganic nutrients and supply oxygen for Atlantic salmon, Salmo salar, in integrated multi-trophic aquaculture systems. Aquaculture 408-409:34-46 
Ren L, Zhang J, Fang J, Tang Q, Zhang M, Du M (2014) Impact of shellfish biodeposits and rotten seaweed on the sediments of Ailian Bay, China. Aquacult Int 22:811-819

Shan XJ, Jin XS, Li ZY, Chen YL, Dai FQ (2012) Fish community structure and stock dynamics of main releasing species in the Bohai Sea. Progress Fish Sci 33(6):1-9 (in Chinese)

Shi J, Wei H, Zhao L, Yuan Y, Fang JG, Zhang JH (2011) A physicalbiological coupled aquaculture model for a suspended aquaculture area of China. Aquaculture 318:412-424

Shi HH, Zheng W, Zhang XL, Zhu MY, Ding DW (2013) Ecologicaleconomic assessment of monoculture and integrated multi-trophic aquaculture in Sanggou Bay of China. Aquaculture 410-411:172-178

Soto D, Aguilar-Manjarrez J, Hishamunda N (eds) (2008) Building an ecosystem approach to aquaculture. FAO/Universitat de les Illes Balears Expert Workshop. 7-11 May 2007, Palma de Mallorca, Spain. FAO Fisheries and Aquaculture Proceedings No. 14. FAO, Rome, p 221

State Forestry Administration (SFA) (2011) The basic situation of forestry in China in 2011. http://www.forestry.gov.cn/ Accessed on October 28,2014

State Oceanic Administration (SOA) (2005-2015). China marine disaster bulletin, 2004-2014. http:/www.soa.gov.cn/Zwgk/hygb/zghyzhgb/ Accessed on March 16, 2015

State Oceanic Administration (SOA) (2013). China marine environment bulletin, 2012. http://www.soa.gov.cn/zwgk/hygb/zghyhjzlgb/ Accessed on June 10, 2015

$\mathrm{Su} J$ (1998) Circulation dynamics of the China Seas: north of $18^{\circ} \mathrm{N}$, In: Robinson AR and Brink K [eds] "The sea," vol. 11, The global coastal ocean: regional studies and syntheses, Wiley, 483-506

Tang QS, Fang JG, Zhang JH, Jiang ZJ, Liu HM (2013) Impacts of multiple stressors on coastal ocean ecosystems and integrated multi-trophic aquaculture. Progress Fish Sci 34(1):1-11 (in Chinese)

Task Force CCICED (2013) Ecosystem issues and policy options addressing the sustainable development of China's ocean and coasts. China Environmental Science Press, Beijing, p 493 (in both Chinese and English)

Wang XP (1998) The nitrogen and phosphorus in sediment interstitial water of cage cultural waters in the Depth Bay of Niutou Island. J Fish Sci China 5(3):126-128 (in Chinese)

Wang R, Zuo T, Wang K (2003) The Yellow Sea Cold Bottom Water-an oversummering site for Calanus sinicus (Copepoda, Crustacea). J Plankton Res 25:169-183
Wang ZX, Sun PX, Liu CX, Liu XJ, Lian Y, Xu RS (2011) The species diversity of macrobenthic fauna in Sanggou Bay, China. Period Ocean Univ China 41(7/8):79-84 (in Chinese)

Wang W, Liu H, Li YQ, Su JL (2014) Development and management of land reclamation in China. Ocean Coastal Manag 102:415-425

Wu CD, Tang TD, Lin ZX, Li WJ (1980) Co-culture of shrimp and mullet. 1980 (3): 11 (in Chinese)

Xie CL (1981) High economic return generated by bivalve and seaweed co-culture. China Fish 1981(5):20 (in Chinese)

Xu ZL, Chen JJ (2010) Analysis to population division and migratory routine of populations and migratory routines of Argyrosomus argentatus in the north China waters. Acta Ecol Sin 30:6442-6450 (in Chinese)

Yang YF, Hou LC, Nie XP, Tang DL, Chung IK (2004) Development of mariculture and its impacts in Chinese coastal waters. Rev Fish Biol Fish 14:1-10

Yang JY, Gao AG, Ning XR, Zhang DS (2007) Characteristics on macrofauna and the responses on aquiculture in Yueqing Bay. Acta Ecolog Ica Sinica 1:34-41 (in Chinese)

Zhai WD, Zhao HD, Zheng N, Xu Y (2012) Coastal acidification in summer bottom oxygen-depleted waters in northwestern-northern Bohai Sea from June to August in 2011. Chin Sci Bull 57(9): 1062-1068

Zhang J, Wu AY, Shi QS (2003) Mariculture and its environment effect in the Xiangshangang Bay. Donghai Mar Sci 21(4):54-59 (in Chinese)

Zhang QC, Qiu LM, Yu RC, Kong FZ, Wang YF, Yan T, Gobler CJ, Zhou MJ (2012) Emergence of brown tides caused by Aureococcus anophagefferens Hargraves et Sieburth in China. Harmful Algae 19:117-124

Zheng XR, Zhang FC, Wu XM, Zhang B, Wang LS (2011) Nutrients in bay scallop culture areas in Changli County. Hebei Fish 205:35-38 (in Chinese)

Zhi YL, Hou JL, Zhang T, Zhang LZ, Zhao F, Yang G, Zhuang P (2013) Spatiotemporal distribution patterns of elver (Anguilla japonica) in the Yangtze River Estuary of China. Chin J Ecol 32(10):2750-2755 (in Chinese)

Zhu YG (1981) Co-culture of clam Meretrix meretrix in a shrimp pond. Mar Fish 1981(2):25 (in Chinese)

Zuo YH, Lin GL (2008) Resource utilization and environment protection in the coastal zone. Science Press, Beijing, p 169 (in Chinese) 